\author{
SECTION OF PATHOLOGY. \\ President-Conolly Norman, F.R.C.P.I. \\ Sectional Secretary, E. J. McWeEner, M.D. \\ Friday, March 26, 1897.
}

Sir C. Nixon, M.D., in the Chair.

\title{
Infective Endocarditis.
}

DR. M. A. BorD read a paper on this subject founded on the case of a man, aged twenty-five, who died at the Mater Hospital after an illness of three days' duration, with extreme pyrexia, delirium, and petechial eruption. At the autopsy there were miliary abscesses in the kidney and myocardium, and the mitral valve presented an area near the margin of one cusp devoid of endocardium, and coated with recent fibrin. The blood was fluid. Sections made from the mitral valve showed extensive necrosis and the margin fringed with compact clusters of cocei. The capillaries of the myocardium were plugged with cocci, and the kidney showed similar conditions. Cultures made during the post-mortem by Dr. MeWeeney produced Pyococeus aureus in pure cultivation. The patient had an alcoholic history, and the illness dated from severe exposure to wet and cold. The mode of entrance of the organisms was otherwise unexplained. Dr. McWeeney demonstrated the sections and cultures.

Dr. E. J. McW Eeney looked upon the case as of considerable interest as indicating a morbid condition extremely liable to be overlooked at an examination not of a very careful character. The miliary abscesses in the kidney were very small, and the condition of the mitral valve was also invisible to the naked eye, but the grave condition was revealed under the microscope. One of the microscopical sections showed the whole of the central portion of one of the little abscesses in the kidney taken up by a zooglœea mass of micrococci. Another section showed the myocardium close to the point of attachment of the mitral valve, and it could be seen that the spaces, normally occupied by capillaries, were plugged with masses of micrococci. From a cultivation the Staphylococcus aureus had been obtained, and a plate cultivation showed the liquefying power of the organism upon gelatine. The organism produced a pale, washy, yellow colour. The organisms had been evidently circulating in the blood of the patient.

The Chalrman said that probably everyone was familiar with 
cases of rheumatic fever undergoing a very bad course where there had been a preceding heart affection. After death the heart, in such cases, presented the ordinary appearance of malignant endocarditis, and the condition seemed to be secondary to a preexisting organic disease. On the other hand, malignant endocarditis was sometimes found as a primary condition. Some writers said that micrococei, similar in character to those which had been found in malignant endecarditis, were found in all forms of endocarditis. An analogy, he thought, might be drawn between cases of malignant endocarditis and cases of acute tuberculosis, in both of which diseases acute primary forms were sometimes found, or acute forms were sometimes grafted on to chronic ones.

Dr. Parsons said that most cases of malignant endocarditis which had come under his notice had had their origin in disease of the middle ear, the septic material haring made its way into the carotid artery or the jugular vein.

DR. BoYp (in reply) said that there was no real indication as to the nature of the case. The symptoms had been those of typhus fever to a great extent, and not till post-mortem examination did the nature of the case dawn upon him. There had been no disease of the middle ear, and no indication at all in any organ of a primary seat of disease.

\section{Lantern Demonstration of $X$-Ray Photos, illustrative of various} Pathological Conditions.

Dr. Lane JoYnt gave, a lantern exhibition of a series of 35 $\mathrm{X}$-ray photos, illustrative of various pathological conditions, and showing the extent and utility of this aid to medieine and surgery. Four cases of Colles' fracture were shown, of which three cases had fracture of the styloid process of the ulna. Dr. Joynt drew attention to the fact that the bones of tuberculous patients re-aeted differently to the $\mathrm{X}$-rays than did sound bone. The most noticeable feature was the homogenous appearance of the ends of bones such as phalanges, with marked atrophy of the compact covering, and in some cases the shafts of the bones are seen to be in a similur condition. The bones, as a whole, are more transparent than sound bone, even in parts not showing the clinical signs of disease.

A skiagraph of the pelvis of a boy, six years old, suffering from congenital dislocation of the hip, showed the complete outline of the bony framework of the body. The condition of luxation conld be plainly seen. The exposure was 20 minutes. An oxalate of lime calculus placed in the kidney of a subject as a control experiment fur cases of suspected renal calculus, under the care of Dr. Mylrs, 
showed clearly. The exposure was 35 minutes in a body $7 \frac{1}{2}$ inches thick.

A skiagraph of elbow of a boy, twelve years old, exhibited a good example of a supra-condyloid process on humerus-the presence of which had caused a doubtful diagnosis of fracture, to be added to that of dislocation of elbow. The case proved to be a dislocation backwards and outwards, of old standing. Dr. Joynt referred to the difficulty of getting useful results in injuries to the shoulder and hip in stout persons-cases where this means would be most valuable-so far, $7 \frac{1}{2}$ inches seemed to be the average limit of thickness, of parts, in which with an 8-inch spark, he had obtained satisfactory results. The right side of the chest permits the rays to pass through better than the left, but no useful results were obtained in cases of suspected aneurysm.

Mr. MrLes said that up till the present the positive information of the X-ray photographs had been worked at, and not the negative. Dislocations of the hip and shoulder were subjects on which they would like to get authoritative information. He had photographed a shoulder which had received a severe injury from the falling of a heavy piece of wood on it. The symptoms, on examination, were almost exactly those of sub-coracoid dislocation of the humerus. The patient was a very muscular man, and on examination under chloroform crepitus was easily obtained, the head of the bone was in its normal seat, and, so far as he could judge, the fracture was somewhere in the neighbourhood of the head of the humerus. The photograph had been a failure. Fracture of the styloid process of the ulna in Colles' fracture was of constant oceurrence. The one case of Colles' fracture which Dr. Joynt had photographed for him was remarkable in that the patient merely complained of a sprained wrist, and when, after his wrist had been photographed, he was told that he had sustained a fracture, he was exceedingly surprised. He referred to the difficulty of obtaining photos of the hip, especially in muscular individuals. The photographs of congenital dislocation in the child were of great interest, as showing that if he could have obtained such information some years ago, three little children would have been saved from the pain of operations from which no benefit had accrued. With reference to the photograph of the hand, he had noticed a curious ramified appearance of the ends of the phalanges and the metacarpal boves in cases of caries of the wrist.

Dr. HaUghton considered the hip joint, at present, almost out of reach of the X-rays, except in cases where the antero-posterior diameter was only seven inches or less. The difficulty, he thought, 
consisted in the presence of the glutei and quadriceps muscles which were of a tendinous nature. There should be no difficulty in locating foreign bodies of a metallic nature. It had been proved that glass was opaque enough to give a shadow.

Dr. McW eENer, in referring to one of the photographs, said that in the removal of parts of bones he had observed that the bones far away from the seat of tubercular lesion showed a sort of sponginess, so that they could be cut like cheese, and that condition was due to a dilatation of the cancellous tissue, and a sort of thinning of the osseous trubeculæ. That might be assigned to a sort of hypoplasia of the whole osseous system. Some writers thought that in tuberculosis sueh a state of cachexia might be produced that absorption of the osseous material could occur.

Dr. Lane JoYnt, in reply, thanked those present for the way in which they had received his communication. He had lately tried to skiagraph a man with aneurysm of the descending aorta, but the shadows had been too indefinite to indicate any thing. He presumed that a shadow thrown by an aneurysm-if thrown - would, in that case, coincide with the view of the heart.

\section{Locomotor Ataxy.}

Drs. Coreman and O'Sullivan brought forward this case. Dr. Coleman detailed the clinical history, according to which it appeared that the patient, a man aged forty-one, a book-keeper, never had syphilis, but he suffered much from exposure to wet and cold. His symptoms began two and a half years before his death with lightning pains in his legs, followed, six months later, by slowness in micturition and occasional incontinence of urine. Fighteen months before his death he had transient diplopia, stumbled in the dark, and felt unsteady on his legs; about the same time he noticed numbness of the fingers of his left hand. The unsteadiness in walking progressed for the next twelve months, at the end of which time he suffered from painful tenesmus and girdle sensation.

On admission to hospital his symptoms were as follows: slightly ataxic gait; inco-ordination of movements of arms; Romberg's sign well marked; tactile sensation deficient over distribution of left ulnar nerve, less so in right hand; thermo-anæsthesia in left arm and both legs, with slight analgesia and retarded transmission of painful sensations; Arggll-Robertson pupil; loss of knee-jerks, and of plantar, cremasteric, and of abdominal reflexes. Nutrition of toe-nails and of skin of soles of feet was much impaired. He had old-standing tuberento-fibroid disease of both lungs, and he 
died five weeks after admission to hospital of disseminated pulmonary tuberculosis.

ProF. O'Sullivan said that the post-mortem examination showed thickening and sclerosis of the aortio valves; eavities, fibroid changes, and bronchiectasis in the right lung and disseminated tubercles in the left. On microscopic examination the nerves of the cauda equina showed increase of endonecerium and marked thickening of the inner coats of the arteries. The cord showed degeneration of the posterior columns, which could be traced from the lower eoccygeal region, where the cord was two millimetres in diameter, to the medulla oblongata. The ventral field of the posterior columns was free from degeneration throughout. $\mathbf{A}$ narrow zone running along the median septum was free in the lower part of the cord. In the dorsal region the medullated fibres of Clark's column had entirely disappeared. The posterior roots outside the cord were markedly degenerated up to about the 5th dorsal segment; from this on to the 2nd dorsal segment they were almost free, and the path of these undegenerated fibres in the cord formed a narrow strip which could be traced along the outer margin of Goll's column to the medulla, where they ended in the nucleus cuneatus. Abowe the 2 nd dorsal segment the degeneration of the posterior roots recurred, and was most marked in the cervical enlargement. Their path in the cord was marked by a strip of degeneration lying outside the last-mentioned and also passing to the nueleus cuneatus. Above the cervical enlargement the degeneration of the jncoming roots suddenly ceased. The degeneration was most marked all through on the left side. Two of the spinal ganglia which were examined showed slight proliferation of the layer of cells lining the spaces oceupied by the ganglion cells.

Dr. M. A. Boxp asked if the peripheral nerves had been examined in the case. Any interference with the peripheral nerves would account, to a great extent, for the symptoms in locomotor ataxy.

Dr. McWrenex considered that Professor O'Sullivan ought to be congratulated on the way in which he had worked out the case. The subject was one which needed thorough-going investigation. He asked if Professor O'Sullivan had examined the posterior roots by Marchi's method. Professor Leyden had lately stated that Weigert's method was incapable of showing a relatively slight amount of degeneration in the posterior nerve roots, but that Marchi's method would show it. Professor Leyden had described certain large round cells as occasionally to be seen surrounding the ganglion cells, and he had also described the same kind of cells, 
which were known as Leyden's cells, surrounding the trophic cells in the anterior horn in cases of infantile paralysis. Did Professor G'Sullivan utilise Pal's method in studying the changes in the ganglion cells?

The Chalrman asked if Professor O'Sullivan considered the condition of the blood vessels in the lower part of the cord a primary or a secondary effect of the lesion.

Profegsor O'Sullivan (in reply) said, in answer to Dr. Bnyd, that the peripherul sensory nerves had been examined. With reference to Dr. McWeeney's questions, he said that in fresh degenerations, when the myeline was altered but not absorbed, Marchi's method was useful. In the case of old chronic processes with selerosis, that method was less and less useful, but he had the very strongest opinion of the usefulness of Marchi's method in almost all forms of degeneration. It was true that degenerations which were absolutely invisible by Weigert's method, showed strongly by Marchi's. He did not think that the cells which he had seen could have been what Dr. McWeeney said were described by Leyden. As regards the study of ganglion cells in general, he used Nissl's method. With reference to Sir C. Nixon's remarks, he (Prof. O'Sullivan) said he had not had sufficient experience to say what lesion was primary or secondary, but he was of opinion that both the lesions of the blood vessels and nerves had the same cause and were independent.

\section{Addison's Disease, with Bilateral Supra-renal Atrophy.}

The Chairman (Sir C. Nixon) showet the viscera from a wellmarked case of Addison's disease. The adrenals were reduced to their shells of fibroid-and fatty tissue, owing to some process of the nature apparently of simple atrophy. Tubercle was conspicuously absent. Dr. McWeeney had prepared sections from the atrophic tissue, and had demonstrated narrow strands of epithelial cells seattered here and there through the mass of fibrous muterial, and representing all that remained of the adrenal cortex. (Sections shown.)

Dr. MeWeEneY said that he, himself, could not have been sure that there would have been such complete destruction of the suprarenal capsules, had he not been at the post-mortem examination himself, and assisted Sir C. Nixon; a very careful dissection had been made. The supra-renals had been reduced to mere shells, and microscopical examination showed a peculiar brown zone of cells between two brilliant red are 1 s of connective tissue. The brown area represented all that remained of the supra-renal cortex. 
Examination had failed to reveal the cause of the destruction. There was a dense mass of fibrous and fatty tissue, in which were embedded some small strands, which represented the only surviving elements of the supra-renals.

The Section ther adjourned.

THE DISINFECTION OF BOOKS BY THE VAPOUR OF FORMALIN.

Elmgr Grant Horton, B.S. (Medical News, New York, LXIX. 6), has tried a series of experiments on the power of formalin to disirfect books. To avoid destruying the books a small piece of paper smeared with twentr-four hour old cultures of the bacilij. of enteric fever, diphtheria, \&c., was placed in folded-down pages; the books were then exposed to formalin under a bell-glassi, and afterwards allowed to stand about for various periods ; finally the infected papers were placed in bouillon at $37^{\circ} \mathrm{C}$, and observed daily for some time. The books were sometimes on their sides and sometimes on end, but were never open, and sometines several were placed in a pile. The conclusions arrived at were:-

1. Books can be disinfected in a closed space, simply by vapour of commercial formalin by using 1 c.c. of formalin to 300 c:c. or less of air.

2. The vapour of formalin is rapid in its disinfectant action. The effect produced in the first fifteen minutes is practically equivalent to that observed after twenty-four hours.

3. An increase in the amount of air to each c.c. of formalin is not counterbalanced by an increase in the length of time of exposure.

4. In case the disinfection has been incomplete, the vitality of the organisms has been so weakened that they survive only if transferred in a few hours to media suitable for their development.

5. The use of vapour of formalin is not detrimental as far as observed in any manner to the books, nor is it objectionable to the operator beyond a temporary irritation of the nose and eyes, somewhat similar to that produced by ammonia.

SUICIDES IN FRANCE

ARE increasing actually as well as relatively. The annual average for the years 1861-65 was 4,661, or 12 per 100,000 inhabitants; for the years $1871-75,5,276$, or 15 per 100,000 inhabitants; for the years 1881-85, 7,339, or 19 per 100,000 ; and for the years $1886-90$, the yearly average was 8,226 , or 21 per 100,000 . 